or sharpen, and are all held in position in the druminto which they can be inserted in a very short timeby four long bolts. These teeth are used until worn
down, and under average working conditions will turn up 3,000 square yards of road

well adapted to any existing that it can be equally effects a great saving of "metal," and is much more efficient and economical than hand labor. The machine works equally well backward or forward, and can be easily attached to a steam roller, and again dethe material. One of these machines has been in use
for some time on Kent roads, and has, we are informfor some time on Kent roads

\section{NOTES ON SILK BLEACHING.}

By \$. J. Pentecost, F.C.S.

WHILE much useful information on the subject of silk bleaching may be obtained from the few books which
treat of silk dyeing, some of the statements made therein are eitherindefinite and misleading or in one or two cases positively erroneous. In the following
notes, I propose to review some of the principal notes, I propose to review some of the pririejpal
methods used, to compare and examine their efficiency, and to mention details of one or two processes more

which the silkworm of the yellow or white filaments the chrysalissstate. The thread issues from the catert. wo smooth cylindrical filaments cemented together by the silk gum, and this it throws around itself to form the cocoon. As soon as completed these cocoons
are collected and heated in ovens, or by steam to $130^{\circ}$ are collected and heated in ovens, or by steam to $130^{\circ}$
F., to kill the pupæ or insects; should these burst in this process, they soil the silk and these cocoons are
put on one side. The outside loose flossy silk-about put on one side. The outside loose flossy silk-about
18 to 30 per cent. of the whole-is removed before
steaming, and with the soiled cocoons is used for spun steaming, and with the soiled cocoons is used for spun silk. more or less different treatment when bleach
these may be conveniently divided as follows :

1. Cultivated silk $\left\{\begin{array}{l}\text { (1.) White and yellow reeled sil } \\ \text { from China and Italy. } \\ \text { (2.) Spun silk. } \\ \text { (3.) Schappe. }\end{array}\right.$

2. Wild silk. .... Tussur.

For the production of the reeled China and Italian the reeling machine, which contains hot water; several
ends are theri taken up and reeled or twisted into a single thread. Two or more of these are again twisted or thrown by the silk throwster, and constitute th
raw silk of commerce. raw silk of commerce.
spun silk is made of the waste silk of the reeling
processes, and consists of silk which cannot be reeled processes, and consists of silk which cannot be reeled
in a continuous thread, viz.: (1.) The external floss silk, with outer and inner por-
tions of the thread.
(2.) Soiled, double and defective cocoons. The silk from these sources is boiled off -all the gum being re-
moved-then combed or carded and spun similarly to moved-then combed or carded and spun similarly to worsted or cotton yarns.
It is not generally known, I believe. that much of the
spun silk produced is tinted, before being spun, with spun silk produced is tinted, before being spun, with
blue or other coloring matter. I have often had cause to suspect that some of the spun silks worked up in
lace fabrics have been weighted also ; and I am inlace fabrics have been weighted also ; and I am in-
cormed that the weighting of waste or spun silk is
carried on to a large extent. It is, therefore, not surcarried on to a large extent. It is, therefore, not sur-
prising that at times silks which look clean and lustrous in the fabric before bleaching and dyeing turn
out poor in color and dull in appearantes after these processes are carried out. The dyer is blamed for the silk spinner or manufacturer. Such practices are to be regretted; and although it is possible to weight
silk up to 60 per cent. without materially impairing its color, luster or strength, such weighting, if re-
quired, should be left to the silk bleacher. Much of the material used for this purpose is liable in con-
junction with the oxidation bleaching processes to junction with the oxidation bleaching processes to
tender the fiber, causing loss and damage. Raw silk
is also sometimes found to be weighted in a similar Nchappe silk is made in the same way as " spun," but
is not boiled off before spinning, being merely softened. In the stripping process it generally gives off a disagreeable odor of decomposed chrysalides.

Tussur silk is the most important of the wild silks. The cocoons are larger than those of the Bombyx
Mori, and are of a grayish fawn color. They are very secretion of the caterpillar which gives to the silk its and spun, the reeling being difficult, although reeled Tussur is much more largely produced than formerly. and under the microscope shows striations which ap-
pear to be small fibrets, cemented together into one Broadly speaking, silk consists of an inner cylinder
of fibroin and an outer coating of sericin or silk gum, the latter being about 20 per cent. to 26 per cent. of
the whole. Reeled Tussur has about 22 per cent. sericin, which may be boiled off. According to Basalcohol, a brown wax-light substance may be obrapidly soluble in soap. Another constituent of TusLime and magnesia salts are present to the extent of about 1 per cent. of the fiber. On calcininir a few
grammes of the fiber in a platinum crucible at low red heat $5 \cdot 34$ per cent
tained as follows:

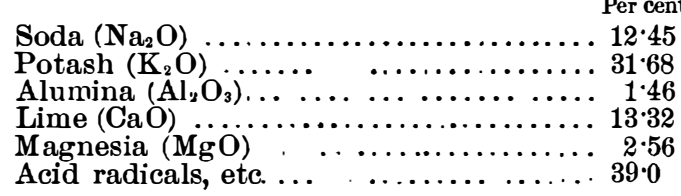

The means adopted for removing this lime will be mentioned further on.
In nearly all cases when silk is to be bleached it is
ut through the preliminary process of stripping and
ing off. STRIPPING. - The operation of stripping consists in orking the silk in a bath of soap solution for about half an hour, with the object of first soaking and moving it, together with the loose dirt, grease, etc.,
which has become attached to the silk during the wanufacturing processes. For this purpose a solution of $13 \mathrm{lb}$. soap in 100 gallons of water is used at
about $190^{\circ}$ F. This liquor, containing the silk gum can afterward be used in dyeing colors, and is known to be observed in carrying out this operation, it is necessary first to insist on the importance of good Hard water, if not passed through a water-softening apparatus, should be softened before use by adding to the water a suitable quantity of pure powdered
98 per cent. caustic soda. Some text books recomrnend the addition of $\mathrm{Na}_{2} \mathrm{CO}_{3}$ for this purpose, but
since many hard waters contain more temporary than permanent hardness, this addition in most cases would only being precipitated, while the bicarbonates would solves at once and removes both permanent and temrary hardness thus :

$\mathrm{CaH}_{2}\left(\mathrm{CO}_{3}\right)_{2}+2 \mathrm{NaHO}=\mathrm{Na}_{2} \mathrm{CO}_{3}+\mathrm{CaCO}_{3}+2 \mathrm{H}_{2} \mathrm{O}$ s an example it may be mentioned that a sample of own water gave on analysis a total hardness of $9 \cdot 8$
arts per 100,000 , comprising $6 \cdot 2$ parts temporary and 3.6 parts permanent hardness. It will thus be seen
that with $\mathrm{Na}_{2} \mathrm{CO}_{3}$ added to this water only $1 / 3$ of the lime would be affected. For a water of moderate he caustic soda may be added to a barque containing 250 gallons of water, and stirred up thoroughly
for three or four minutes before use. Should this precipitation of lime salts be neglected, a quantity of
sticky lime soap is fixed upon the silk during the
stripping and boiling operations which in turn serves to fix any suspended matter which may tur into th to fix any suspended matter which may get into the The quality of the soap to be used for stripping and
Thent suled boiling off requires careful attention. In a recent one for this purpose. The only point in its favor,
however, is that it is not decomposed by hard water with formation of lime soap. Its disadvantages are An excess of caustic alkali is inevitable in a thoroughly saponified cocoa nut oil soap, making it unsuitable for a similar reason, viz., that it attacks the animal Ter, unsuitable for ungumming silk.

The soap used must be free from caustic alkali, must odor. Potash soaps made from olive oil, tallow, or soap rinses out more difficultly than either olive oil or soap rinses out more difficultly than either olive oil or Therefore, having regard to the comparatively high
price of olive oil, I consider the best soap for silk is a potash soap made from a good white tallow olein.
Cotton seed olein is not so good, and is likely to leave objectionable smell on the goods. Potash soap is appears to preserve the luster, etc., of the silk betsilk lustrous and with an agreeable odor.

ould seem to be best for a perfectly neutral soap is found in practice that a soap made slightly alkane with $\mathrm{K}_{2} \mathrm{CO}_{3}$ gives on the whole somewhat betalkalinity arising from caustic potash or soda

BoILING OFF. - The silk after being stripped is, in
Buterious to the be case of lace, fabrics, etc., put into boiling bags to
be boiled off. The bags are loosely made of thick hempen cord, and then filled and tied at the top and by fire as well as steam. In the case of hank silk, the specially constructed machines. The silk is then
boiled in about 15 per cent. of soap, or speaking more correctly, a solution of soap containing $7 \mathrm{lb}$. of soap ing to the quality and thickness of the silk. After
finsing first in warm, then in cold water, the silk is BLEACHING. - The several methods used in bleach
Bdy for bleaching. BLEACHING. - The several methods used in

- Bleaching by treatment with acid

(a.) Gas bleaching.
(b.) Liquid bleaching.

. Bleaching by oxidation-

a.) Permanganate potash method

(c.) Sodium peroxide.

1. Acid Treatment. - The first method is frequently bleaching raw yellow silk the sulphuring process fo the object of which is to gain the luster and feel of boiled-off silk without removing the gum, or with the carried out as follows: The yellow silk is first soft-
ened and cleaned by working for about an hour in a warm bath of 10 per cent. soap. It is then well regia at about $3^{\circ}$ or $4^{\circ} \mathrm{I} w$. The aqua regia is made by
mixing 5 parts commercial hydrochloric acid mixing 5 parts commercial hydrochloric acid with silk lies in this acid bath until it turns greenish.
It is then taken out, well washed, sulphured and soupled. in place of aqua regia a dilute solution of sulphuric
acid in which an $\mathrm{OH}$ group bas been replaced by an
$\mathrm{NO}_{2}$ group, thus:

$\mathrm{SO}_{2}\left\{\mathrm{HO}_{2}\right.$
This is obtained by saturating the oil of vitriol with of chamber crystals obtained in the manufactu $e$ of by working in a 10 per cent. soap solution at $70^{\circ} \mathrm{F}$
. or 1 hour is well washed and entered into the acid it is allowed to lie in this bath too long, it contracts yellow tint. It is then well washed and may be ng about 1 hour in acidulated water at $190^{\circ}$ to $200^{\circ} \mathrm{F}$. in the usual way.

This acid treatment can be used also to improve the

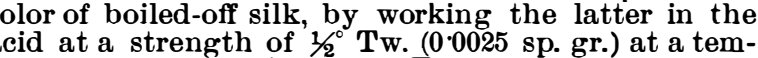
2. Reduction Methods. - In
.

methods the coloring matter of the silk is destroyed by the reducing action of sulphur dioxide either in in use for several centuries, the exposure of silk and wool to sulphur fumes being a very old process. As
at present carried out, the silk is hung up and spread out in a chamber generally termed the sulphur stove,
heated to $90^{\circ}$ or $100^{\prime}$ F., which can be securely closed to confine the fumes. The requisite amount of suldoors being securely closed. After six hours (or all night), the doors are thrown open; the gas allowed
to escape ; and the silk being taken out, is washed to goods by oxidation of the sulphur dioxide. The amount of sulphur to be burned should have some relation to the size of the chamber, and the percent-
ages of sulphur given which have regard only to the quantity of silk to be bleached are therefore not always
reliable. About $1 / 2 \mathrm{lb}$. sulphur per 1,000 cubic feet of stove room is a suitable quantity.
This process gives a distinct improvement in the
color of the silk, but its effect is by no means permanent. Exposure to light and air gradually brings owing to reoxidation. A passage through soap or an vantage gained by sulphuring; hence it is very little
use for goods which have subsequently to be dyed light colors in a soap bath. It is, however, very sideration.

Bleaching by Sodium Hydrosulphite.-Quite re-
cently another substance which exerts a reducing accently another substance which exerts a reducing action upon the coloring matter of the silk has been ap-
ylied for bleaching, viz: Hydrosulphite of soda, Na-
$\mathrm{HSO}_{2}$. To prepare it a clean bleached tob of 50 . $\mathrm{HSO}_{2}$. To prepare it a clean bleached tub of 50 galls.
capacity may be taken. Into this are put 32 galls. of bisulphite of soda at $66^{\circ}$ Tw. (1.33 sp. gr.) and scraps of pure zine are added until they reach the surface of are taken, if necessary, to prevent the temperature
rising too high ; earthenware tubes being sometimes suspended in the tub through which cold water circu-
lates. The liquid is then drawn off into another tub which is filled and covered up to prevent oxidation, sodium sulphites to crystallize out. The supernatant liquor is the bleaching agent, and is also kept covered up in a full tub to avoid oxidat
hydrosulphite is formed thus :

$\mathrm{NaHSO}_{3}+\mathrm{Zn}=\mathrm{NaHSO}_{2}+\mathrm{ZnSO}_{3}+\mathrm{Na}_{2} \mathrm{SO}_{3}+\mathrm{H}_{2} \mathrm{O}$ For use it is only necessary to dilute the standard bleaching agent with an equal volume of water, enter bath for six hours; after which they are well wrung and immediately washed. If this washing is delayed, luster and strength. The silk should then be run traces of sodium and zinc sulphites, which would produce yellow stains on finished goods, and finally watiled $\mathrm{NaHSO}_{2}$, and will thus last for a considerable time. The undissolved zinc can also be made again servicewith HCl. Oxidation Methods.-Several substances which exert an oxidizing action upon the silk have been tried at various times for bleaching it. One of those most
used before the introduction of the peroxides was potassium perrmanganate. Its action depends upon of organic matter. The silk was steeped in a dilute in an acid bath which dissolved off the brown hydrate ormed in the reaction.

The use of permanganate has, however, practically
ceased, since hydroger peroxide has been put on the ceased, since hydroger peroxide has been put on the
market at much lower prices than formerly.
Bleaching with Hydrogen Peroxide. - This reagent has now been in use for bleaching some 18 or 20 years.
Silk bleached by it was exhibited at the Paris Exhibition of 1878. It is only during the last few years, ase. It is made from peroxide of barium by introduc-
ing the latter gradually into a calculated quantity of ing the latter gradually into a calculated quantity of cess, which takes about 12 hours, is carried on in a copwater; great care being taken to prevent a rise in water; great care being taken to prevent a rise in
temperature. The hydrofluoric acid may be regener-
ated from the bariun fluoride formed by means of
$\mathrm{H}_{2} \mathrm{SO}_{4}$. The $\mathrm{BaO}_{2}$ is also sometimes decomposed with sulphuric or carbonic acid. Hydrogen peroxide may
also be produced, as follows : Finely ground barium pitch, and heated in a furnace to a temperature of $1,000^{\circ} \mathrm{C}$. The barium oxide thus obtained is cooled to $50^{\circ}$ C., at which temperature it absorbs oxygen fron
the air. The $\mathrm{BaO}_{2}$ is then mixed with water and decomposed by a current of carbon dioxide. The hydrocen peroxide formed is then decanted off and the pregen peroxide decomposes very easily, and should be kept in a cool, dark place when stored, to prevent loss
of oxygen. It is more stable when slightly acid than when neutral or alkaline. According to the experi-
ments of Kingzett, published in the journal of the Society of Chemical Industry, 1889, its stability is further 
maintained by addition of alcollol, while of the acids, phosphoric acid appears to best preserve the strength. or barrels-the former should be preferred, since in them the strength and color are better maintained. The exact meaning of the term "volume strength" across one or two statements to the effect that 10 manganate of potash produces 10 volumes of oxygen. This is plainly an error, since one-half the amount of oxygen is furnished by the permanganate, and such a of available oxygen. A 10 volume solution is such as contains 10 times its own volume of available oxygen. ancertain strength of many peroxides at present sold becomes very necessary that every lot should be carehydrogen sold in this country as 12 volume varies in strength from $41 / 2$ volume to 9 volume. Several methods of estimation are avallable, viz.

faint pink color is obtained. Two of potash until a faint pink color is obtained. Two grammes of the per-
oxide are taken, diluted with 50 c. c. distilled $\mathrm{H}_{2} \mathrm{O}$ and oxide are taken, diluted with 50 c. c. distilled $\mathrm{H}_{2} \mathrm{O}$ and of potash until the pink color appears, the perroxide being first acidulated with about 2 c. c. of $\mathrm{H}_{2} \mathrm{SO}_{4}$. The
percentage and then the volume of $\mathrm{H}_{2} \mathrm{O}_{2}$ may be cal-
culated. The reaction is as follows : $\mathrm{K}_{2} \mathrm{Mn}_{2} \mathrm{O}_{8}+3 \mathrm{H}_{2} \mathrm{SO}_{4}+5 \mathrm{H}_{2} \mathrm{O}_{2}=$ $2 \mathrm{MnSO}_{4}+\mathrm{K}_{2} \mathrm{SO}_{4}+8 \mathrm{H}_{2} \mathrm{O}+5 \mathrm{O}_{2}$

Each c. c. of $\frac{\mathrm{N}}{100} \mathrm{~K}_{2} \mathrm{Mn}_{2} \mathrm{O}_{8}$ taken corresponds to 0.56 volume, or 0.17 per cent. $\mathrm{H}_{2} \mathrm{O}_{2}$, and . $\cdot 2$ grms. $\mathrm{H}_{2} \mathrm{O}_{2}$ of 12 volume strength would require 21.5 c. c. $\frac{\mathrm{N}}{100}$ $\mathrm{K}_{2} \mathrm{Mn}_{2} \mathrm{O}_{8}$

2. It may also be accurately estimated by addition of $\mathrm{K}_{6} \mathrm{Fe}_{2} \mathrm{Cy}_{12}+2 \mathrm{KHO}+\mathrm{H}_{2} \mathrm{O}_{2}=$ $2 \mathrm{~K}_{4} \mathrm{FeCy}_{8}+2 \mathrm{H}_{2} \mathrm{O}+\mathrm{O}_{2}$.

This reaction takes place with quantitative exactness excess. A nitrometer (Lunge's) may be used for the stimation.

3. The strength may be estimated also by adding
potassium iodide to an acid solution of peroxide, and phate and starch

4. A much readier method for practical use, and one which gives approximately accurate results, may be
described as follows : A 50 c. c. graduated tube closed at one end is filled with water up to about the $28 \mathrm{c}$. mark, and a little $\mathrm{H}_{2} \mathrm{SO}_{4}$ (say $1 \mathrm{c}$. c.) added $: 1 \mathrm{c}$ c. c. of from a burette : the thumb placed on the mouth of tube, the latter inverted, and the volume of air read then loosely wrapped up in a bit of tissue paper and then loosely wrapped up in a bit of tissue paper and
dropped into the tube; the thumb is immediately
placed over the tube mouth to make it gas tight, while placed over the tube mouth to make it gas tight, while oughly for two or three minutes. The tube is then
plunged into a glass cylinder of cold water, mouth plunged into a glass cylinder of cold water, mouth temperature, and the volume read off. After deducttained, one half of the residual volume obtained repreSents the volume of oxygen available in the sample. and care must be taken to keep it tightly on the tube mouth to preverit escape of gas.

A consideration of the temperature at which the
bleaching is performed may enable us to speak of the bleaching is performed may enable us to speak of the viz.: (1) the cold method; and (2) the warm method. quantity of 12 volume peroxide with three times a quantity of 12 volume peroxide with three times its to cause the bath to smell faintly of it, and cause
small bubbles of oxygen to slowly rise to the surface. The goods are immersed in this liquid for one, two or three days, according to the amount of bleaching re-
quired. As a rule, it is unwise to leave groods in this quired. As a rule, it is unwise to leave goods in this luster and strength are likely to suffer. Borax, oxide of magnesium, silicate of soda, and other substances vantages are dealt with further on in speaking of Tussur bleaching. at 1 part of 12 volume $\mathrm{H}_{2} \mathrm{O}_{2}$ to 10 parts water or 1 part to 20 of water, according to the amount of bleaching
the silk requires. An addition is made to the bath of ammonia, or preferably for this method one of the ammonia, or preferably for this method one of the
above named substances : the silk is entered, worked
for one-fourth hour, gradually hested up to $190^{\circ} \mathrm{F}$. during one hour, and then worked for three-four
hour at this temperature, washed and scrooped.

Sodium Peroxide. - Quite recently there has been
introduced a new product for bleaching silk, viz.: introduced a new product for bleaching silk, viz.: manufacture as described by Mr. Castner, thepatentee, consists in treating metallic sudium contained in aluminum vessels at a temperature of $300^{\circ} \mathrm{C}$., to the gradual oxidizing action of a mixture of oxygen and ually increased. This is done in an iron pipe which passes through the furnace and along which a current
of air is passed from one end. The vessels containing the sodium pass along the entire length of the pipe, been almost deprived of its oxygen, the proportion of the latter gradually increasing until it is finally oxi-
dized by air containing the full amount of oxygen. This method is not unlike that pursued in the manu facture of barium peroxide, in which $\mathrm{BaO}$, prepared at a high temperature in a retort, air being allowed to at a high temperature in a retort, air being allowed to
pass in at gme end and nitrogen to escape at the
other.

The average analysis of $\mathrm{Na}_{2} \mathrm{O}_{2}$ (for which I
debted to Mr. F. Burton, of London) shows :

Peroxide sodium Per cent
$93 \cdot 0$

Carbonat

Hydrate

Compared with $\mathrm{BaO}_{2}$ and $\mathrm{H}_{2} \mathrm{O}_{2}$ (10 vols.) solution, 93 per cent. sodium

peroxide............ 19.5 per cent. available $O$.

peroxide............

It is a yellowish white partially powdered substance which dissolves in water with a hissing sound and
great evolution of heat. These characteristics are possibly partly due to particles of metallic sodium
rom which the peroxide is made. As at present devered to the consumer it is by no means free fromimpurities, and dark colored particles are found which
might be expected to be slightly prejudicial to its might be expected to be slightly prejudicial to its
bleaching effect. It is strongly alkaline and very deliquescent. In keeping it care must be taken to keep materials, such as cotton, paper, etc. If kept dry, it more stable than $\mathrm{H}_{2} \mathrm{O}_{2}$, and if used carefully it comes cheaper. The makers claim for it that $1 \mathrm{lb}$ is equal in
bleaching power to $1 \frac{2}{5}$ gallons of 10 volume $\mathrm{H}_{2} \mathrm{O}_{2}$. They bleaching power to $1 \frac{2}{5}$ gallons of 10 volume $\mathrm{H}_{2} \mathrm{O}_{2}$. They
recommend its conversion into $\mathrm{H}_{2} \mathrm{O}_{2}$ by adding it recommend its conversion into $\mathrm{H}_{2} \mathrm{O}_{2}$ by adding it solntions without the use of suitable cooling arrange ments, much loss of oxygen results and the ultimate
product is much dearer than ordinary $\mathrm{H}_{2} \mathrm{O}_{2}$. To make
10 gallons of 10 volume $\mathrm{H}_{2} \mathrm{O}_{2}$ take $103 / 4 \mathrm{lb}_{2} \mathrm{H}_{2} \mathrm{SO}_{4} 168^{\circ}$ Tw., mix with 8 or 9 gallons $\mathrm{H}_{2} \mathrm{O}$ and cool. Then add
71 , lb. sodium peroxide gradually and with con$71 / 2$ lb. sodium peroxide gradually and with con-
tinual stirring, special cooling arrangements being
used to keep temperature low, without which it would used to keep temperature low, without which it would It is, however, better in practice to make the $\mathrm{Na}_{2} \mathrm{O}_{2}$
into $\mathrm{H}_{2} \mathrm{O}_{2}$ of 1 volume strength or such strength as is required for bleaching. in order that the extra water required may be utilized to cool the whole, and so pre-
vent escape of oxygen. Thus a 1 volume $\mathrm{H}_{2} \mathrm{O}_{2}$ bath may be made by adding to 94 gallons of water $101 / 4 \mathrm{lb}$.
$\mathrm{H}_{2} \mathrm{SO}_{4} 168^{\circ}$ Tw., previously diluted with 2 gallons

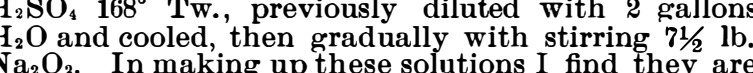
Na $\mathrm{O}_{2} \mathrm{O}_{2}$ In making up these solutions I find they are always slightly colored yellowish brown; and on was found to consist of oxide of iron. This impurity is the most serious defect of the sodium peroxide at be able in the future to eliminate it. It can, however,
be got rid of by a suitable addition to the bath, which carries it down to the bottom of the vessel. Another later under the head of Tussur bleaching.

Bleaching of T'ussur Silk. - In conseguence of the
ecretion which permeates the silk of the Tussur cocoon being more difficult of removal than in the case
cond the of cultivated silk, other and keener substances are
sometimes used in the stripping bath, such as caustic sometimes used in the stripping bath, such as caustic reeled Tussur to determine the best scouring agent to in stripping and boiling off :

\section{No. 1 , stripped $1 / 2$ hour
and boiled 1 hour in..}

No. 2. do. do.

No. 3. do. do.

No. 4 , steeped 1 night $(12$

hours) in a bath con-
taining in three pints
water.................

No. 4 looked cleanest and best, No. 3 better colo were practically equal results. These four samples No. 4 did not bleach well, the turpentine evidently interfering with the result. Nos. 1,2 and 3 appeared so lustrous.

or culdiver bleaching processes which are still useful sur, and the latter can only be bleached sittisfictorily ny the use of per methe have been proposed, in which
other reagents are used previous to the peroxide bath,
but the best of these produce no better result than but the best of these produce no better result than
when peroxide is used alone, as will be shown by the bleaching trials given further on, while the luster and
feel are more or less inpaired by them. Professor feel are more or less innpaired by them. Professor tion of the sulphuring and peroxide methods (see Hurst, tion of these processes is correct, viz., thiat they act by reduction and oxidation respectively, the one process might be expected to neutralize the effect of the other.
This appears to be so in practice. So far as Tussur This appears to be so in practice. So far as Tussur washed and bleached in a peroxide bath of 2 volume ferior to a second sample bleached in the same strength Another method given for bleaching Tussur silk in
nniment. Mr. Hurst's recently published book on silk dyeing, steep the silk in a bath of $22 \mathrm{lb}$. caustic soda, $66 \mathrm{lb}$. peroxide of hydrogen, and a little ammonia. This bath would not simply bleach the Tussur, but would dissolve it. It was really recommended by Koechlin
for bleaching cotton with hydrogen peroxide and does not give "excellent results" with Tussur as stated by
Mr. Hurst. The following method was proposed by Ch. Girard,
and has been applied for bleaching Tussur spun silk and has been applied for bleaching Tussur spun
on the Continent:
1 . Work in warm dilute HCl (1 to 8) for 1 hour,
2. Wash and strip with sodium carbonate or 2 per cent. caustic soda, and wash.
3 Steep in hypochlorite of ammonia for 24 hours. 4. Wash, pass through dilute $\mathrm{HCl}$ and wash.

5. Steep in hydrogen peroxide of one-half volume The first hydrochloric acid bath is beneficial, in that removes the lime present in Tussur silk, but the treatment with ammonium hy pochtoritebefore bleachcess, and no advantage can be gained by its use, as the following bleaching trials show:
No. 1 sample was stripped half an hour and boiled one hour in $1 / 4$ oz. $\mathrm{Na}_{2} \mathrm{CO}_{3}$ to 1 pint water.
No. 2 was steeped in warm dilute $\mathrm{HCl}$ ( 1 .

No. 2 was steeped in warm dilute $\mathrm{HCl}$ ( 1 in 6 ) for one hour, washed, then stripped and boiled as No. 1, and
steeped in hypochlorite of ammonia at $1^{\circ} \mathrm{Tw}$. for 24 No. 3 was treated as No. 2 , but steeped in hypochlorite of soda at $1^{\circ} \mathrm{Tw}$. for 24 hours.

All three were washed and separately steeped in
$\mathrm{H}_{2} \mathrm{O}_{2}$ (1 vol.) with 2 c. c. AmHO added to $22 \mathrm{oz}$. for three days, then washed and scrooped.

No. 1 gave the best result both in color and luster. No. 3 became tender in the $\mathrm{Na}_{2} \mathrm{Cl}_{2} \mathrm{O}$ solution-1 $1^{\circ} \mathrm{Tw}$.
being evidently too strong-but as $\mathrm{No}^{-1}$ gave best olor the trial was not repeated. The ammonium hypochlorite was made by adding $11 / 2$
oz. $\mathrm{Am}_{2} \mathrm{CO}_{3}$ dissolved in $1 / 2$ pint water to 1 oz. bleach-
ing powder rubbed down in $1 / 2$ pint water, allowing to ing powder rubbed down in $1 / 2$ pint water

The sodium fypochlorite was made by mixing $5 \%$ oz.
s. oaching powder in 1 pint water, and 31 oz. crystal arbonate in $1 \frac{4}{5}$ pints water; the latter is added to the carbonate in $1_{5}^{4}$ pints water; the latter is added to the former mixture gradually ; the mixture becoming much
thicker, and then suldetrly thin again near the com-
pletion of the reaction. It was then allowed to settle, and the liquor poured off for use. Experiments were then made to determine the best
and most economical strength of peroxide of hydrogen to use in bleaching. Three samples of reeled Tussur tripped, and boiled in $\mathrm{Na}_{2} \mathrm{CO}_{3}$ solution $1 / 4$ oz. to the
pint, then steeped in peroxide of hydrogen solution as

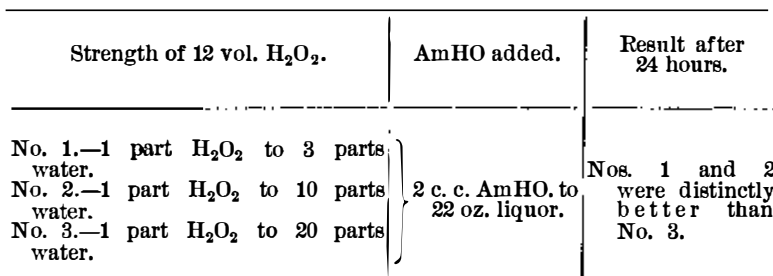

Left them in bleach three days.

On the second day there was a slight improvement third day they were heated in their respective liquor to $190^{\circ} \mathrm{F}$. for two hours. This treatment improved
the color considerably without impairing the luster perceptibly. After heating No. 1 was slightly better A third series of experim superior to No. 3.

A third series of experiments was made to determine gen bath, with a view to producing the best color consistent with strength and luster. Four samples of reeled Tussur prepared as indicated in previous series
were bleached in 12 vol. $\mathrm{H}_{2} \mathrm{O}_{2}$ diluted with 10 times it weight of water, with various additions as follows :

\begin{tabular}{|c|c|c|}
\hline $\begin{array}{l}\text { Additions made } \\
\text { to } 22 \text { oz. peroxide } \\
\text { liquor. }\end{array}$ & $\begin{array}{l}\text { Result after } \\
1 \text { day. }\end{array}$ & $\begin{array}{l}\text { Result af ter } 2 \text { thy cold } \\
\text { bleaching, the ch } \\
\text { heating to } 190^{\circ} \mathrm{F} \text {. in } \\
\text { respective liquors. }\end{array}$ \\
\hline $\begin{array}{l}\text { No. 1. } 2 \text { c. c. } \mathrm{AmHO} @ \\
0.880 . \\
\text { No. } 2.1 / 4 \text { oz. } \mathrm{Na}_{2} \mathrm{~B}_{4} \mathrm{O}_{7} \ldots\end{array}$ & $\begin{array}{c}\text { Better than } 2 . \\
\text { Inferior to } 4 . \\
\text { Darker than others. }\end{array}$ & \}About alike. \\
\hline No. 3. 逍 oz. $\mathrm{MgO} \ldots \ldots \ldots$ & Same as No. $1 \ldots . .$. & . Slightly better than 1 \\
\hline $\begin{array}{l}\text { No.4.43 oz. } \mathrm{Na}_{2} \mathrm{SiO}_{3} @ \\
140^{\circ} \mathrm{Tw} .\end{array}$ & $\begin{array}{l}\text { Clearest. Rather } \\
\text { yellower than } \\
\text { others. }\end{array}$ & Much the best. \\
\hline
\end{tabular}

No. 4 gave a very good result. It was a clear good Soliminished. Peroxide.-Very good results may be obSodium Peroxide. - Very good results may be ob-
tained by bleaching Tussur with sodium peroxide by the following method recently patented by Dr. Haen.
For $50 \mathrm{lb}$. of Tussur a bath is prepared containing 30 For $50 \mathrm{lb}$. of Tussur a bath is prepared containing 30 with off and well washed is thoroughly impretynted ide of sodium are carefully added in three portions during three-quarters of an hour, working the silk in neglect the first impregnation with $\mathrm{M}_{\mathrm{O}} \mathrm{S} \mathrm{S}_{3}$, solution, as
solution the luster would be impaired by the strongly alkaline peroxide of sodium acting upon the silk. The whole
is then gradually heated during three-quarters of an Dilute sulphuric acid is then added to clear the liquor, which has become milky through separation of magnesium hydrate. The material is given two or three turns in this liquor, washed, and then worked for half restore its luster, washed and brightened by stringThe reaction which takes place appears to be the following :

$\mathrm{MgSO}_{4}+\mathrm{Na}_{2} \mathrm{O}_{2}=\mathrm{Na}_{2} \mathrm{SO}_{4}+\mathrm{MgO}+\mathrm{O}$

Samples bleached by this method gave a color scarceperoxide and sodium silicate; the luster, however, was

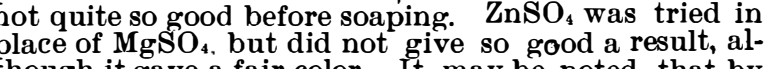
hough it gave a fair color. It may be poted, that by
working silk after bleaching for half an hour in a 30 porking silk after bleaching for half an hour in a 30
per cent. soap bath, afterward washing and scrooping, especially with Tussur. In concluding I desire to ac- 
knowledge the assistance of Mr. Furley Davis in carrying out the bleaching trials

In the discussion which followed, the chairman among other things said : As to peroxide of sodium, he was glad Mr. Pentecost had referred to the dangerous nature of the chemical, which would easily set fire to it had become spilled if water were dropped upon it.Jour. Soc. Chem. Ind.

IMPROVEMENTS IN GALVANIZING IRON. G. Retterer, Paris, France.

IN the ordinary manufacture of galvanized iron by dipping there is a considerable production of hard

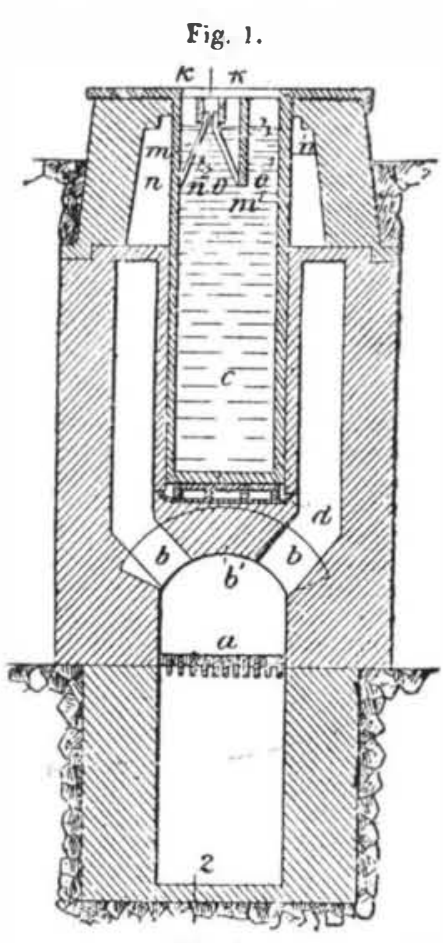

Fig. 2.

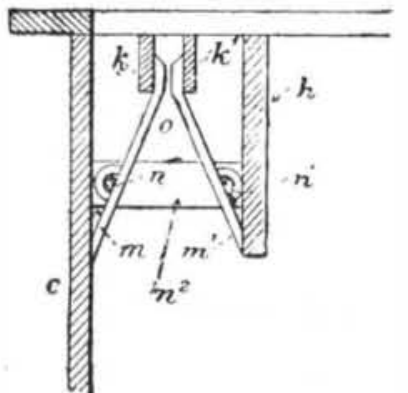

APPARATUS FOR GALVANIZING IRON.

cessity of uncovering the metal while the sheet is being withdrawn. This invention consists in mechanical means for overcoming these difficulties. The apparacompartments by the partition, $h$. The bath, compartment, $o^{1}$, are filled with lead. The bath, $c$, and $o$, contains spelter, which floats on the lead. In the compartment, $o$, at the surface of the spelter are two movable bars, $k$, $k^{2}$ (Fig. 2 ), supported by rods, $m, m^{1}$, pivoted at $n, n^{1}$. In order to coat a plate it is thrust into the compartment, $o$, and submerged until its up-
per edge is below the partition, $h$. It is then released and floats upward, pushing apart the bars, $k, k$, which the metal is covered. A small clear space is thus produced sufficient for the removal of the sheet. The surface of the lead in the compartment, $o$, is covered with sal-ammoniac.

IMPROVEMENTS IN MELTING FURNACES.

\section{F. H. MALLAHAND, Kirkcaldy, London.}

THIs is a furnace for general melting purposes, and can be used either with coke or gaseous fuel. If the
former is used the metal is placed in a crucible, $O$, which

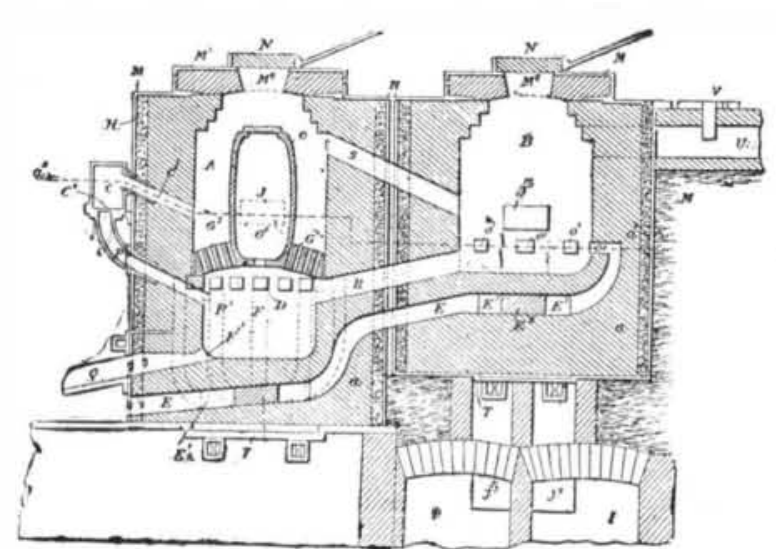

IMPROVED MELTING FURNACE

is then packed round with coke. An air blast passes from the box, $c$, through tubes, $c^{1}$, of which there are several, into the furnace, $A$. It also passes through $P$ and $\mathrm{P}^{1}$ into a lower compartment, $\mathrm{F}$, which receives shown by the dotted lines, to allow of the removal of samples from $F$ and for rabbling. The products of combustion from the furnace, $A$, pass through $\mathbf{S}$ into $\mathrm{B}$, and finally escape to the chimney through U. The
furnace, $\mathrm{B}$, contains scrap, or metal receiving a prelim- inary heating before being transferred to $A$. Any meta The openings, $\mathrm{D}, \mathrm{D}^{1}$, in the two furnaces communicate with a channel, $\mathrm{E}$, and are for the escape of slag. Th channel, $E$, is kept hot by the gases passing from $A$ to
$B$. The metal is drawn off through the spout, $Q$. If gaseous fuel is to be used the crucible is removed, the
arch, $G$, completed, and the body of the furnace filled arch, $G$, completed, and the body of the furnace filled
with the metal to be melted. The blast in $C$ is cut off, the flue, U, closed, and two ports, $\mathbf{J}, \mathbf{J}^{5}$, are opened. Each of these communicates with a pair of regenerators, conveying air and gas respectively, and the flame is passed from $A$ to $B$ and from $B$ to $A$ as the pairs of down

EXTRACTION OF GUTTA PERCHA. The invention of Dieudonne Rigole, of Singapore for extracting gutta perch a from the leaves and twigs of isonandras, dichopsis or other gutta percha tree by the use of carbon bisulphide, thus avoiding the common practice of cutting down these valuable tre
which require twenty-five years to reach maturity.

which require twenty-five years to reach maturity. is to be extracted are suitably pounded so as to un is to be extralsentaining the pound are introduced into an exhausting vessel, $A$.

The carbon bisulphide is put in the boiler, $\mathrm{B}$, passes through the tube, $a$, in a state of vapor into the condenser, C, where it condenses and then traverses the pounded leaves and twigs. The condensed vapors
from the bisulphide containing the soluble principles from the bisulphide containing the soluble principles
then return to the boiler, B, through the tube, $a^{\prime}$, the then return to the boiler, $\mathrm{B}$, through the tube, $a^{\prime}$, the
lower part of which is provided with an automatically operating flap, $b$, for permitting the passage of the gum into the boiler, B. Across the bore of the tube, $a^{\prime}$, is placed a very thin wire gauze, $c$, serving as a
filter or rather as a strainer. After the bisulphide has collected a certain portion of the gum, which it conducts to the boiler, $\mathrm{B}$, where the same is deposited, it in the space, $C$, and recommen its exhausting operation until the gum contained in the leaves and twigs

Other solvents than carbon bisulphide would give milar results, such as benzine, chloroform and the like, but the price of these substances, which I have tried, augments the cost of the gutta percha so much cial purposes.

If use is made of benzin as a solvent, the gumee, lected will man of benzine as a solvent, the gum colelimination of which presents almost insuperable diffeliminaties.

\section{CUT NAILS AND WIRE NAILS.}

THe following is a summary made by consulting engineer William H. Burr from the detailed official Ordnance Department U. S. A., in command of the United States Arsenal at Watertown, Mass., and of the United States testing machine at that station, showcertaining the relative holding powers of cut nails and wire nails, of equal lengths and weights: which tests were made at the United States Arsenal at Watertown, Mass., under the supervision of Major Reills, in accordance with an invitation of the Eastern cut nail manufacturers of the United States to the wire nail manufacturers of the United States, dated November , 1892. The tests were made in November and Decem-
ber, 1892, and January, 1893:

The series of tests, each series comprising ten pairs of cut
nails and wire nails of one size, were, in number......

nails and wire nails of one size, were, in number.......
The number of nailis tested was........................
The nails ranged in length from

sumber of selding power whas the cut nails showed the
she number of geries in which the wire nails showed the superior holding power was.........
All the nails tested were driven in.

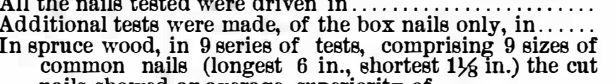

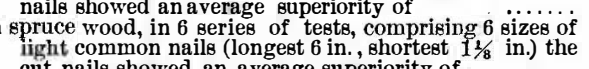

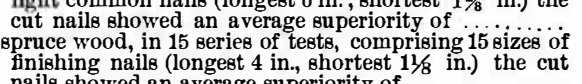
58
1160
$11 / 8$ to 6 in.

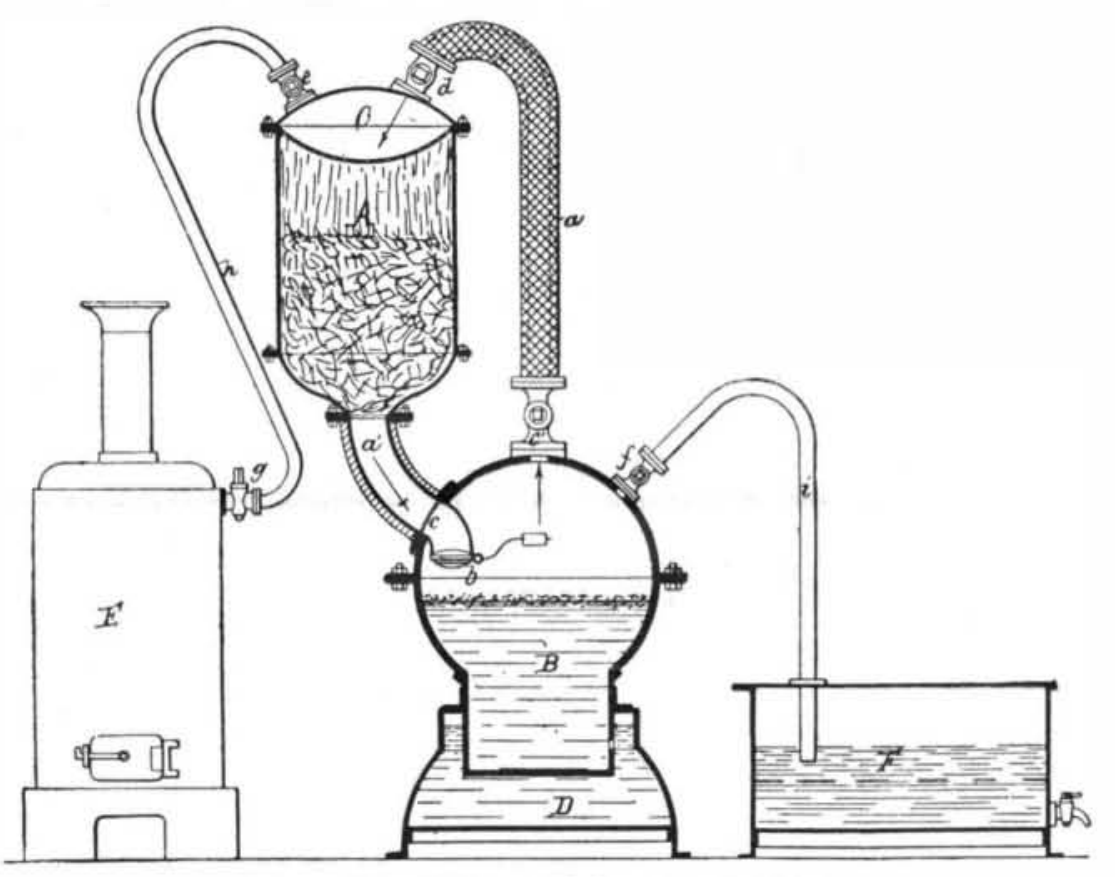

EXTRACTION OF GUTTA PERCHA.

in the vessel, A, has been completely extracted. The tubes, $a$ and $a^{\prime}$, are surrounded by a sleeve of cotton, bisulphide which is continually being puritied by the distillation must in a short time effect the complete exhaustion of the leaves and twigs. Of course the carbon bisulphide contained in the boiler, B, must become quite oxidated, which inconvenience is obthe said boiler in a water bath, D $45^{\circ}$ Centigrade. vessel, $\mathrm{A}$, by a tube, $h$, provided with cocks, $e$ and $g$. A tube, $i$, provided with a cock, $f$, leads from the boiler, $\mathbf{B}$, to a vessel, $\mathbf{F}$. When the exhaustion of the the boiler, $\mathrm{B}$, to the tube, $a$, is closed to prevent the communication of the boiler, $\mathrm{B}$, with the tube, $a$. I
also close the cock, $d$, which connects the tube, $a$, also close the cock, $d$, which connects the tube, $a$,
with the vessel, $\mathrm{A}$, and open the cocks $e, f$ and $g_{3}$ and introduce into the vessel, A, a powerful jet of superthrough the tube, $h$, and passes into the boiler, $B$,
through the tube, $a^{\prime}$. It will carry away the few globules of gum which may still be in the leaves and twigs,
traverse the tube, $a^{\prime}$, in order to pass to the boiler, B, traverse the tube, $a^{\prime}$, in order to pass to the boiler, $B$,
containing the gutta percha in solution in the carbon containing the gutta percha in solution in the carbon
bisulphide, and introduce the vapors through the bisulphide, and introduce the vapors through the
cock, $f$, into the discharge tube, $i$, the extremity of in the assel. $\mathrm{F}$. The e inon bisuiphide in the vessel, F. The carbon bisulphide having a the bottom of the vessel, F. When the gum has all been extracted from the leaves and twigs, the gutta percha is in a liquid state mixed with the solvent. As
the steam carries away the carbon bisulphide and precipitates it in the bath, $F$, the gutta percha in the boiler, B, thickens, and when the last traces of th solid body but capable of being kneaded if put into warm water. In order that no bisulphide shall remain in the gum the introduction of superheated steam may be prolonged in such a manner that the gutta percha will not be affected

The complete operation ought not to occupy more than twenty-two to twenty-five

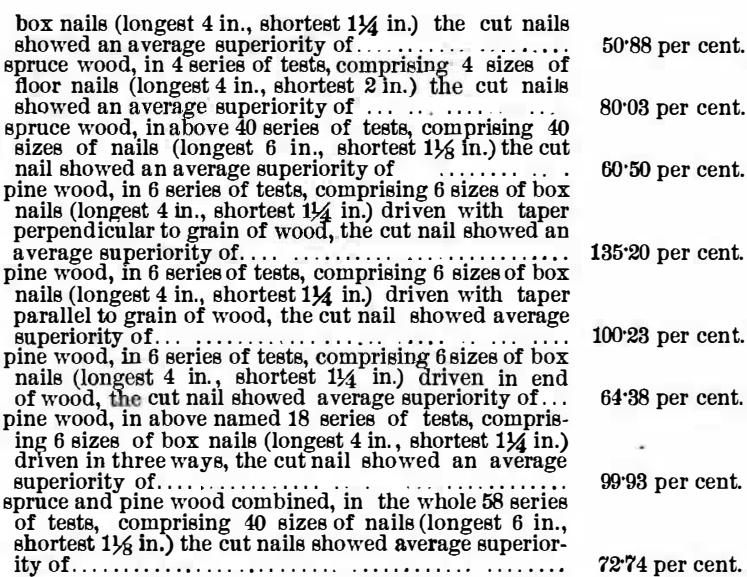

MAGNESIA FIREBRICKS

Som $\mathrm{E}$ weeks ago, at a meeting of the French Society

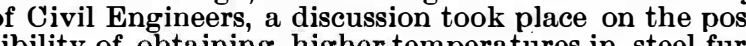
tem obtaining higher temperatures in steel furat which the walls of the furnace begin to fuse, and Magnesia is claimed to be capable of standing far higher temperatures than the Diners brick. It is used according to a statement made at the meeting referred to, by M. Lencauchez, and was first proposed by M. $\mathbf{E}$. Muller in 1869. The principal difficulty in using it is the excessive shrinkage to which it is liable when heatraw state is said to shrink to one of 6 -in. edge when made of this material were liable to crack badly. The remedy for this state of things is to cause the magnesia to undergo its maximum possible contraction before being placed in the furnace, but

These difficulties have, it is claimed, now been over-
Thely high temperature is required. come, and M. Lencauchez showed the Paris Society of magnesia, which were as dense as granite, and had even Diners firebricks are not proof against this. 